\title{
The impact of climate warming on species diversity across scales: Lessons from experimental meta-ecosystems
}

\author{
Vinicius A. G. Bastazini ${ }^{1}$ (D) | Núria Galiana ${ }^{1}$ | Helmut Hillebrand ${ }^{2,3,4}$ | Marc Estiarte $^{5,6}$ | \\ Romá Ogaya $^{5,6}$ | Josep Peñuelas ${ }^{5,6}$ | Ulrich Sommer ${ }^{7}$ | José M. Montoya ${ }^{1}$ (D)
}

${ }^{1}$ Centre for Biodiversity Theory and Modelling, Theoretical and Experimental Ecology Station, French National Center for Scientific Research and Paul Sabatier University, Moulis, France

${ }^{2}$ Institute for Chemistry and Biology of Marine Environments (ICBM), Carlvon-Ossietzky University Oldenburg, Wilhelmshaven, Germany

${ }^{3} \mathrm{Helmholtz}$ Institute for Functional Marine Biodiversity (HIFMB), University of Oldenburg, Oldenburg, Germany

${ }^{4}$ Alfred Wegener Institute (AWI), Helmholtz Centre for Polar and Marine Research, Bremerhaven, Germany

${ }^{5}$ CSIC, Global Ecology Unit CREAF-CSICUAB, Bellaterra, Catalonia, Spain

${ }^{6} \mathrm{CREAF}$, Cerdanyola del Vallès, Catalonia, Spain

${ }^{7}$ GEOMAR Helmholtz Zentrum für Ozeanforschung Kiel, Kiel, Germany

\section{Correspondence}

Vinicius A. G. Bastazini, Centre for Biodiversity Theory and Modelling, Theoretical and Experimental Ecology Station, French National Center for Scientific Research and Paul Sabatier University, Moulis 09200, France.

Email: bastazini.vinicius@gmail.com

\section{Funding information}

Region Midi-Pyrenees project, Grant/ Award Number: CNRS 121090; TULIP Laboratory of Excellence, Grant/Award Number: ANR-10-LABX-41 and ANR-11IDEX-002-02; H2020 European Research Council, Grant/Award Number: 726176; Spanish Government, Grant/Award Number: CGL2016-79835-P; European Research Council Synergy, Grant/Award Number: ERC-SyG-2013-610028 IMBALANCE-P

Editor: Amanda Bates

\begin{abstract}
Aim: The aim was to evaluate the effects of climate warming on biodiversity across spatial scales (i.e., $\alpha$-, $\beta$ - and $\gamma$-diversity) and the effects of patch openness and experimental context on diversity responses.

Location: Global.

Time period: 1995-2017.

Major taxa studied: Fungi, invertebrates, phytoplankton, plants, seaweed, soil microbes and zooplankton.

Methods: We compiled data from warming experiments and conducted a metaanalysis to evaluate the effects of warming on different components of diversity (such as species richness and equivalent numbers) at different spatial scales ( $\alpha-, \beta-$ and $\gamma$-diversity, partitioning $\beta$-diversity into species turnover and nestedness components). We also investigated how these effects were modulated by system openness, defined as the possibility of replicates being colonized by new species, and experimental context (duration, mean temperature change and ecosystem type).

Results: Experimental warming did not affect local species richness ( $\alpha$-diversity) but decreased effective numbers of species by affecting species dominance. Warming increased species spatial turnover ( $\beta$-diversity), although no significant changes were detected at the regional scale ( $\gamma$-diversity). Site openness and experimental context did not significantly affect our results, despite significant heterogeneity in the effect sizes of $\alpha$ - and $\beta$-diversity.

Main conclusions: Our meta-analysis shows that the effects of warming on biodiversity are scale dependent. The local and regional inventory diversity remain unaltered, whereas species composition across temperature gradients and the patterns of species dominance change with temperature, creating novel communities that might be harder to predict.
\end{abstract}

\section{KEYWORDS}

$\alpha$-diversity, $\beta$-diversity, climate change, habitat fragmentation, manipulative experiments, meta-analysis 


\section{1 | INTRODUCTION}

Climate change and its consequent increase in average global temperature are already affecting important biological processes, such as rates of species dispersion, phenologies, range distributions, community assembly and biotic interactions (Cahill et al., 2013; Lurgi et al., 2012; Peñuelas et al., 2013; Scheffers et al., 2016). These changes are likely to accelerate extinction rates at the global scale in the coming decades (Urban, 2015), with important consequences for the provision of crucial ecosystem services (Bulling et al., 2010; Pecl et al., 2017; Peñuelas et al., 2017; Scheffers et al., 2016), for local livelihoods and for the global economy (Lee et al., 2015; Stern, 2015).

Our understanding of the effects of warming on the biota is centred primarily on the responses of single species or on various measures of local diversity (i.e., $\alpha$-diversity; Antão et al., 2020; Araújo \& Luoto, 2007; Gruner et al., 2017; Wiens, 2016). Recent syntheses of the impacts of global change on $\alpha$-diversity have spurred controversy. Some studies suggest declines in local average species richness (e.g., Cardinale et al., 2018; Gonzalez et al., 2016), whereas others suggest that the average number of species is roughly constant over time (e.g., Dornelas et al., 2014; Vellend et al., 2017). The effects of warming on other important aspects of biodiversity, such as changes in differentiation diversity (i.e., compositional similarity among local communities, such as $\beta$-diversity) and higher levels of inventory diversity (i.e., diversity within spatial units, such as $\gamma$ diversity) at the regional level are not fully elucidated.

Measures of $\alpha$-diversity, especially species richness, are insensitive to many possible changes within communities in response to environmental change (Hekkala \& Roberge, 2018; Hillebrand et al., 2018). A focus on species diversity at the level of individual local communities limits our ability to understand spatial and temporal changes of ecosystems in response to both natural and anthropogenic factors (Chase et al., 2018). Identification of the independent effects of global warming in different components of species diversity is challenging, because warming is likely to be confounded with other environmental stressors, such as habitat loss and fragmentation.

The consequences of warming across local communities can be measured by metrics of $\beta$-diversity. Changes in $\beta$-diversity can identify two important and contrasting phenomena, namely nestedness (communities with fewer species are subsets of richer communities) and spatial turnover (the replacement of species in one community by different species in another community; Baselga, 2010; Baselga et al., 2007). Nestedness can indicate non-random processes of species loss and/or gain across space, representing differences in the sensitivity of species to environmental gradients or disturbances. Turnover implies that the replacement of a set of species across a gradient is driven by differences in the optimal niche, leading to environmental sorting or historical constraints (Baselga, 2010; Baselga et al., 2007). An understanding of the processes driving changes in $\beta$-diversity provides crucial information to understand the impact of warming, assisting decision-makers to choose relevant spatial scales for conservation (Bergamin et al., 2017; Legendre et al., 2005). For instance, high levels of nestedness in open patches across a thermal gradient might indicate that species are being lost systematically at higher temperatures, and this loss cannot be compensated by dispersal or recolonization across the patches of habitat. High levels of species turnover, in contrast, might suggest that a particular set of species is being selected to occupy specific sections of the new climatic gradient (e.g., Hillebrand et al., 2010), forming novel communities (Urban et al., 2012; Williams \& Jackson, 2007).

The establishment of causal connections between changes in climate and biodiversity poses an extra challenge because nonexperimental field studies rely on correlational data, which make inferential interpretation troublesome (Stewart et al., 2013). Experimental meta-ecosystems offer a solution to this limitation, because they provide a unique opportunity to comprehend and predict responses of biodiversity to warming (Stewart et al., 2013), mimicking climatically induced changes in meta-ecosystems with different levels of habitat patchiness and isolation.

Here, we present the results of a meta-analysis devised to evaluate the effects of increasing average temperatures on biodiversity across spatial scales (i.e., $\alpha$-, $\beta$ - and $\gamma$-diversity). Recent syntheses on the effects of experimental warming have evaluated its effects on species diversity at local scales (Gruner et al., 2017). Thus, the knowledge of how warming affects biodiversity across spatial scales is an open and crucial question to be answered, in order to improve our ability to anticipate and mitigate its effects. Given that the processes that shape diversity patterns are spatially structured (Chase et al., 2018), we expect that responses at the local scale ( $\alpha$-diversity within replicates) will differ from responses at larger spatial scales ( $\gamma$-diversity of the experimental system), and that warming will have a deleterious effect on $\alpha$-diversity and increase rates of nestedness in $\beta$-diversity through a systematic loss of species less adapted to the new climatic conditions. This implies that $\gamma$-diversity should be unaltered, given that richer patches should have levels of species diversity similar to the levels of the regional pool.

Our meta-analysis also evaluates the effect of important moderators, because previous meta-analyses showed that the effects of warming on experimental meta-communities depend on the experimental design itself, including differences in the temperature and time of manipulation and the ecosystem type (Gruner et al., 2017; Marino et al., 2018). Given that habitat fragmentation has been shown to aggravate the effects of climate change in ecological communities (Oliver et al., 2015; Opdam \& Wascher, 2004), we expect open patches, defined as the possibility of replicates being colonized by new species, to be less prone to lose species or, at least, more likely to recover from species loss, because individuals from resident species are able to migrate and (re)colonize open patches.

\section{MATERIALS AND METHODS}

\section{1 | Data}

We compiled data from published meta-community experiments (mesocosms or microcosms), encompassing ecological communities 
(individual replicates) subject to warming and their corresponding controls. We used the search engines of the ISI Web of Science and Google Scholar with cross-referencing to find studies published between 1995 and 2017, using the same search string as the one used by Gruner et al. (2017), who conducted an earlier meta-analysis of the effect of warming on $\alpha$-diversity: "(temperature or warming) AND (diversity or evenness or richness) AND (experiment*or mesocosm*or manipu**)". We also included additional studies identified in the course of the literature review, following relevant citation tracks. Our search identified 131 studies published world-wide. We contacted authors to request raw community data, in order that we could calculate a standardized measure of $\beta$-diversity for each dataset.

Based on primary data, we were able to extract 67 datasets (from 28 studies; a list of the data sources is given in Supporting Information Appendix S1) that were used in our analyses. We excluded datasets that used a temperature manipulation $(\Delta T)$ of $>6^{\circ} \mathrm{C}$, because this exceeds the most extreme projections for global temperature increase by the end of the 21st century (Stocker et al., 2013). When studies reported manipulations at multiple temperatures, we averaged the experimental temperature, as long as $\Delta T<$ $6^{\circ} \mathrm{C}$. If $\Delta T$ was $>6^{\circ} \mathrm{C}$ in one of the treatments, we used only data from sampling units with experimental temperatures $<6^{\circ} \mathrm{C}$. We also excluded studies that we were not able to reconstruct local communities (at the replicate level) from the original data. In the case of studies with multiple factors besides warming, we partitioned the data into independent subsets within the levels of the other factors in order to estimate biodiversity metrics and effect sizes.

\subsection{Measures of diversity across scales}

Firstly, we computed two measures of $\alpha$-diversity, namely species richness [i.e., the total number of identified taxa or operational taxonomic units (OTUs)] and the effective number of species derived from Hurlbert's probability of interspecific encounter (ENS. Pie; Chase \& Knight, 2013; McGlinn et al., 2019). ENS.pie represents the number of equally abundant species in a perfectly even community (Chase \& Knight, 2013; McGlinn et al., 2019). It offers many advantages over other diversity indices in meta-analytical approaches, because ENS.Pie is scale independent (i.e., relative insensitivity to sample grain and extent) when communities are distributed randomly (Chase \& Knight, 2013) and it is an unambiguous metric of effect size (Chase \& Knight, 2013). Thus, ENS.pie allows one to disentangle sampling effects from treatment effects that would alter the mechanisms of coexistence of species in the experiment (Schuler et al., 2017).

Secondly, we calculated the $\beta$-diversity among replicates within any given study and partitioned it into species turnover and nestedness components using two different approaches: (a) based on qualitative data (i.e., species presence/absence; see Baselga et al., 2007); and (b) based on quantitative data. For quantitative data, we computed nestedness, measuring the abundance gradient and species turnover as the balanced variation of abundance (Baselga, 2010, 2013). This method uses matching components in terms of species abundances to provide a partition of $\beta$-diversity, separating two components of abundance-based dissimilarity: (a) balanced variation in abundance, in which individuals of some species in one site are substituted by the same number of individuals of different species in another site; and (b) abundance gradients, in which some individuals are lost from one site to the other (Baselga, 2013). Metrics of $\beta$-diversity range from zero (lowest dissimilarity) to one (highest dissimilarity), and in both cases, the partition is additive, enabling the measurement of the total dissimilarity of experimental communities (Baselga, 2013).

Thirdly, we calculated $\gamma$-diversity for both warming treatments and the control, by counting the total number of species or OTUs at the end point of each experiment.

\section{3 | Meta-analysis}

We calculated the logarithmic response ratio (InRR; Borenstein et al., 2009) as our measure of effect size for all indices of $\alpha$ - and $\beta$-diversity. The $\ln R R$ is a measure of the relative effect size (i.e., the proportional change in the response variable relative to the controls). Given that there is no replication at the study level to estimate the variance for $\gamma$-diversity, we estimated the raw difference between control and impact $\gamma$-diversity $(\Delta \gamma)$ as a measure of the effect size (Borenstein et al., 2009) at the meta-community level. We evaluated differences in $\gamma$-diversity using ANOVA, logIn-transforming species richness values.

To evaluate the effect of warming on $\alpha$ - and $\beta$-diversity, we first fitted random-effect models using the InRR as response variable, with the dataset identity as a random intercept. We measured heterogeneity $\left(\mathrm{I}^{2}\right)$ of this random model as a means to access the total variance component that was not explained by sampling variance (i.e., the percentage of total variation across studies that is attributable to heterogeneity rather than to chance itself; Higgins et al., 2003).

To answer the remaining questions (the effect of site openness and experimental context), we then fitted meta-regression models, using four experimental moderators: $\Delta T$ (difference between control and warming treatments, in degrees Celsius; range: $0.23-5^{\circ} \mathrm{C}$ ), study length (in days; range: 15-7,300 days), ecosystem type (categorical, coded as dummy variables: freshwater, terrestrial and marine) and patch openness (binary state: system open or closed to migration of individuals), which measures the potential of individual replicates to receive new species. This moderator was used as a proxy of patch openness for natural communities.

We evaluated the effects of each moderator on each level of diversity using a multi-model inference approach within an information-theoretical framework (Burnham \& Anderson, 2002). To evaluate model plausibility, we used the Bayesian information criterion $(\mathrm{BIC})$ and $\mathrm{BIC}$ weight $\left(\mathrm{BIC} w_{i}\right)$, which measures the relative likelihood of the model given the data, normalized across the set of 
candidate models to sum to one for all possible models (Burnham \& Anderson, 2002). We also evaluated the importance of each moderator by computing its relative importance value based on the BIC for all possible models. The information-theoretical approach taken here allows the assessment and comparison of the support of several competing models, based on the probability of each model being the best model in the set of candidate models. The relative importance of a moderator (within the range $0-1$ ) is the probability that a given moderator appears in the best model, and it is estimated by summing the weights of each model where that moderator appears. It is important to stress that we took this approach in order to extract all the information from the set of possible models, and not to select the "best" model. This approach also allowed us to estimate the weighted average value for each model parameter (i.e., slopes and intercepts). We estimated a weighted averaged slope for each moderator based on all possible nested models and their respective model plausibility, measured by the $\mathrm{BICw}_{j}$ (Burnham \& Anderson, 2002). We evaluated the significance of each moderator, building $95 \%$ confidence intervals for each averaged model parameter.

To estimate the effects of site openness and experimental context on $\gamma$-diversity, we used linear models within the same multimodel inference approach, using $\Delta \gamma$ as the response variable. All analyses were conducted in the R environment (R Core Team, 2012).

\section{3 | RESULTS}

\subsection{Effects of warming on diversity}

Experimental warming had no significant effect on species richness locally, but significantly reduced the effective number of species (ENS.Pie), which decreased on average by $4.4 \%$ in warming replicates when compared with controls $(\operatorname{InRR} \pm S E=-0.0450 \pm 0.02$ $z$-value $=-2.2456 ; p=.02$; Figure 1 ). For both controls and warming replicates, ENS.Pie was smaller than the observed richness. This reduction suggests that warming has a detrimental effect for rare or less frequent species and a beneficial effect for dominant species, resulting in less equitable communities in warming replicates. Random models for $\alpha$-diversity (i.e., richness and ENS.Pie) presented high and significant heterogeneity (mean $I^{2} \pm S D=79.73 \pm 1.22$; Figure 1).

Species turnover (or the balanced gradient in species abundance in the case of quantitative data) was the main component of total $\beta$ diversity (ANOVA $p$-values <.001; Figure 2). Overall, experimental warming had no consistent effect on $\beta$-diversity, except for qualitative species turnover, which increased on average by $5.8 \%$ (InRR $\pm S E=0.0563 \pm 0.0208 ; z$-value $=2.7066 ; p=.007 ;$ Figure 3 ) when compared with controls. The overall mean effect size for all other measures of $\beta$-diversity was not different from zero (Figure 3). All models for $\beta$-diversity presented significant heterogeneity (mean $I^{2} \pm S D=46.53 \pm 17.45$; Figure 3 ), with nestedness components being more heterogeneous than turnover components (Figure 3 ).

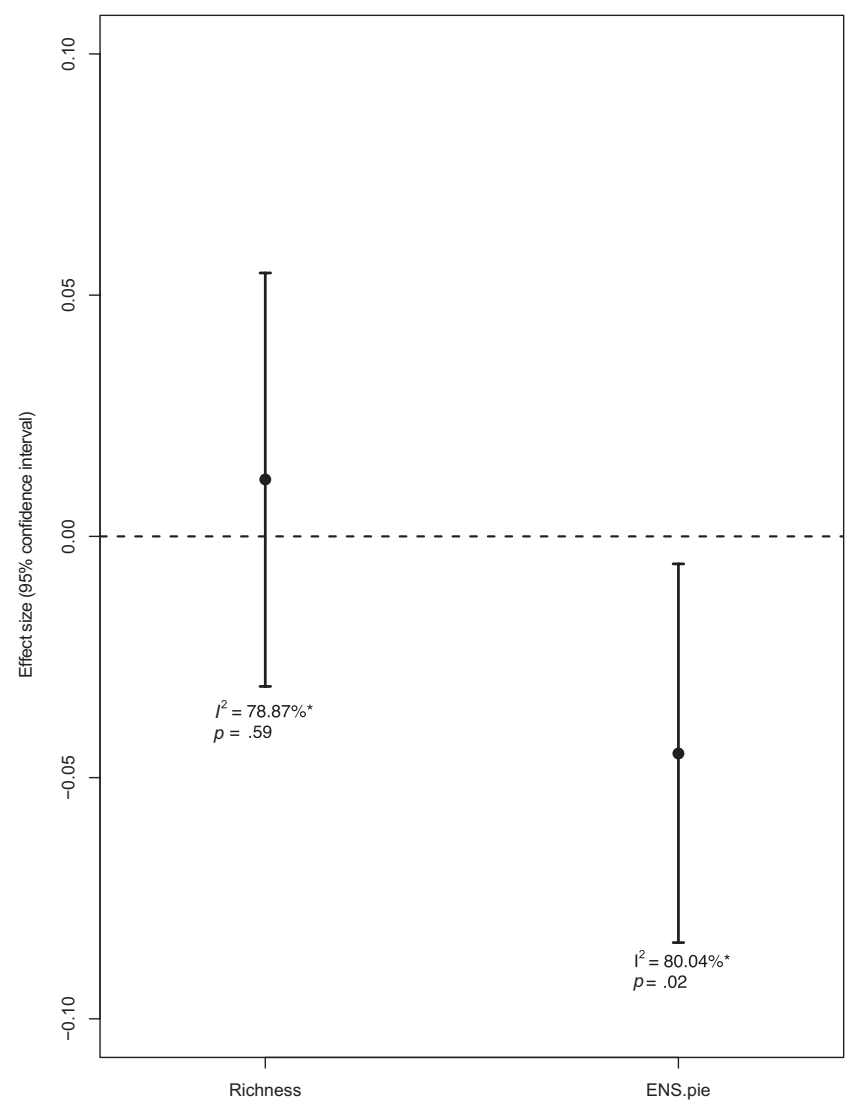

FIGURE 1 Mean effect size $\pm 95 \%$ confidence intervals from temperature-change experiments on both components of community $\alpha$-diversity, namely species richness and the effective number of species (ENS.Pie). $I^{2}$ represents the amount of heterogeneity (i.e., variation in effect sizes) that is not accounted for by the sampling error variance. Confidence intervals above (or below) the dashed line show significant positive (or negative) effect sizes. Asterisks indicate a significant $(p<.05) l^{2}$

The increase of species turnover implies that warming is not causing net species gain or loss at the replicate level, with more tolerant species persisting in warming environments. This increase in species turnover did not affect the total number of species at the regional level (i.e., $\gamma$-diversity) in warmed meta-ecosystems $\left(F_{1,132}=0.008 ; p=.93\right)$. The average raw difference showed that $40.3 \%$ of the meta-ecosystems lost species at the species pool level, whereas $37.31 \%$ gained species, with the remaining $22.39 \%$ of the datasets showing constant species richness $\left(\chi^{2}=5.52\right.$, d.f. $=$ $2 ; p$-value $=.06$ )

\subsection{Openness and experimental context as mediators of the effects of warming}

Contrary to our initial expectations, patch openness had no significant effect on any component of diversity (Table 1; Supporting Information Figures S1-S3). Ecosystem type was amongst the main moderators explaining differences in the effect size for species richness, with terrestrial and marine systems having larger effect 
Incidence-based

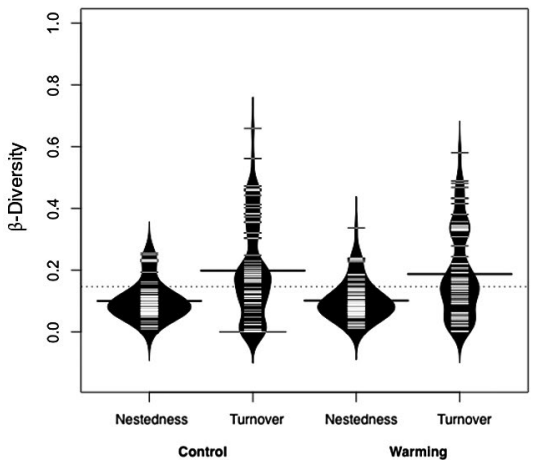

Abundance-based

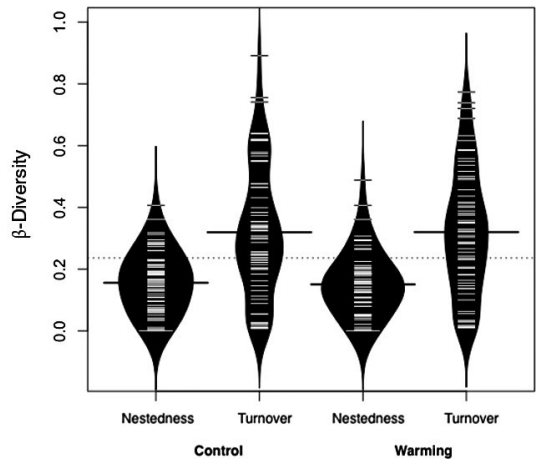

FIGURE 2 Bean plot showing differences in spatial turnover and nestedness for both incidence-based indices and abundance-based indices. Values of $\beta$-diversity close to zero represent low dissimilarity, whereas values close to one represent high dissimilarity. Lines represent individual observations. The shaded areas show the distribution density. Thick lines represent the averages within each level. Dotted lines indicate the global average

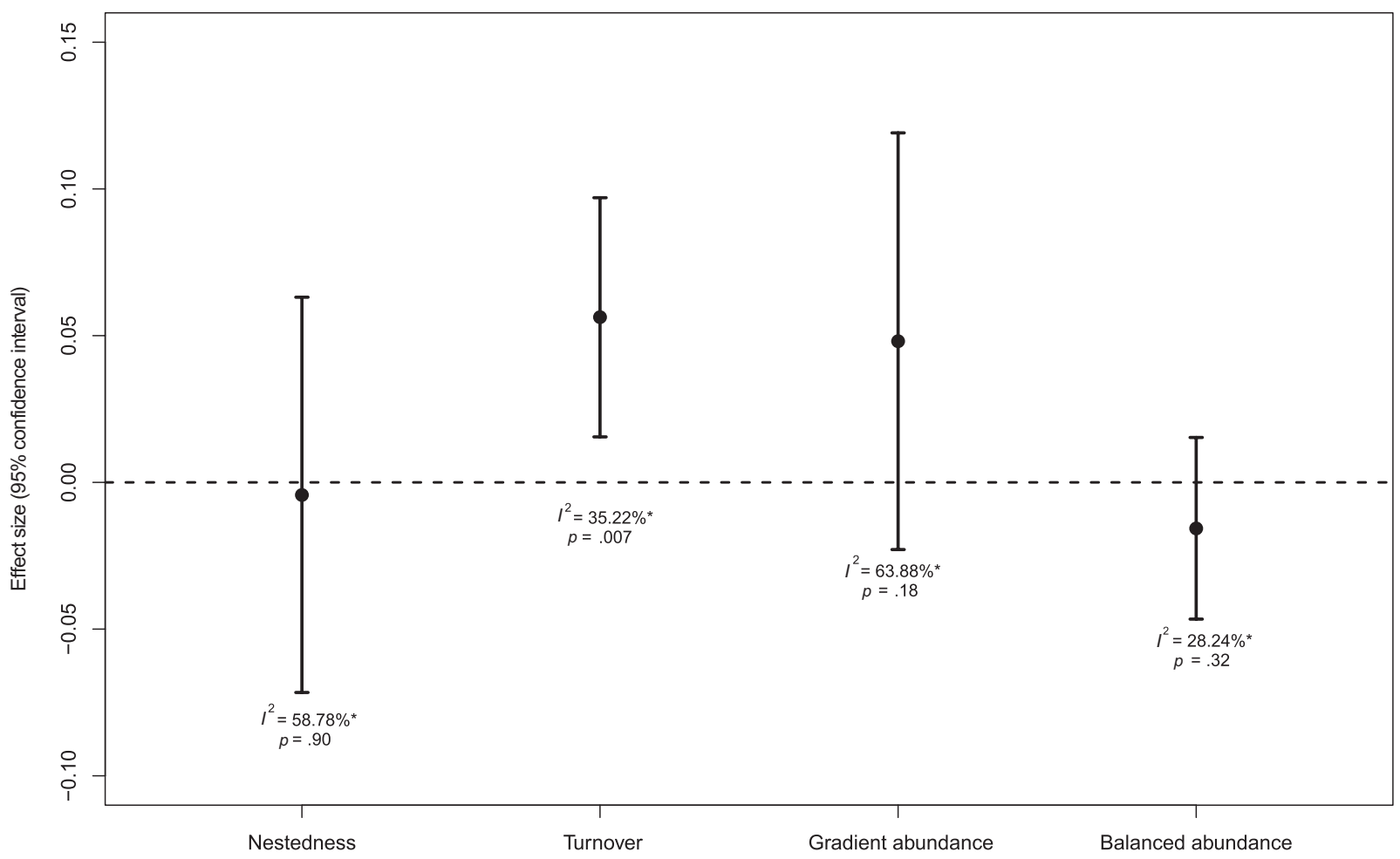

FIGURE 3 Mean effect size $\pm 95 \%$ confidence intervals from temperature-change experiments on different aspects of community $\beta$-diversity. Nestedness and turnover are incidence-based measures, whereas gradient and balanced abundance are abundance-based measures. $I^{2}$ represents the amount of heterogeneity (i.e., the variation in effect sizes) that is not accounted for by the sampling error variance. Confidence intervals above (or below) the dashed line show significant positive (or negative) effect sizes. Asterisks indicate a significant $(p<.05) I^{2}$

sizes for richness than freshwater systems (Table 1; Supporting Information Figure S1). Experimental $\Delta T$ had a significant effect on explaining the variation in species richness. On average, $\Delta T$ was among the top moderators explaining differences in effect sizes for $\beta$-diversity (Supporting Information Figure S2), although no slope differed from zero. Study duration had no significant effect on $\alpha$-, $\beta$ - and $\gamma$-diversity results (Table 1 ; Supporting Information Figures S1-S3).

\section{4 | DISCUSSION}

\subsection{Effects of warming on components of diversity}

We know little about the effects of climate change on biodiversity across spatial scales. Our meta-analysis found that experimental warming did not affect local species richness, but altered the patterns of species dominance at the local scale and species turnover 
TABLE 1 Model-averaged parameter estimates of moderators of $\alpha$-, $\beta$ - and $\gamma$-diversity, based on all possible models

\begin{tabular}{|c|c|c|c|c|c|c|c|}
\hline Moderator & Richness & ENS.Pie & \multicolumn{2}{|l|}{ Incidence } & \multicolumn{2}{|l|}{ Abundance } & Gamma \\
\hline$\Delta T$ & $0.044(0.040)$ & $-0.002(0.09)$ & $0.007(0.027)$ & $-0.025(0.055)$ & $0.076(0.057)$ & $-0.001(0.004)$ & $0.011(0.167)$ \\
\hline Openness & $-0.003(0.022)$ & $-0.003(0.017)$ & $-0.001(0.018)$ & 0.031 (0.109) & $0.007(0.039)$ & $-0.003(0.019)$ & $-0.071(0.556)$ \\
\hline Study duration & $0(0)$ & $0(0)$ & $0(0)$ & $0(0)$ & $0(0)$ & $0(0)$ & $-0.001(0.001)$ \\
\hline Terrestrial & $0.268(0.131)$ & $0.144(0.246)$ & $-0.002(0.011)$ & $-0.066(0.166)$ & $0.001(0.009)$ & $-0.009(0.033)$ & \\
\hline
\end{tabular}

Note: Values in parentheses represent the alpha risk for confidence intervals $(\alpha=.05)$. Bold values indicate significant slopes.

ENS.Pie = effective number of species; $\Delta T=$ temperature manipulation.

across space. Warming decreased the effective number of species (ENS.Pie) and increased spatial turnover, which in turn led to small increases in $\gamma$-diversity in some ecosystems. Chase and Knight (2013) have demonstrated that ENS.Pie should become increasingly lower than richness as the level of equitability decreases. Decreases in ENS.Pie respond to decreases in species evenness and not richness, suggesting a consistent effect on relative species abundance, with some species becoming more dominant in warmed systems. Changes in dominance seem to be a recurrent response to warming (Harte \& Shaw, 1995; Hillebrand et al., 2008; Kosten et al., 2012; Yvon-Durocher et al., 2015). Although increased local species dominance can lead to an increment of cascading extinctions (Zarnetske et al., 2012) and higher levels of $\beta$-diversity (Hillebrand et al., 2008), this effect was not strong enough to be detected by abundancebased measures of $\beta$-diversity.

Our results for $\alpha$-diversity contrast with those reported in the meta-analysis by Gruner et al. (2017), in which warming decreased species richness, whereas it had no effect on species evenness (although evenness decreased significantly in terrestrial systems). The difference between our results and those of Gruner and colleagues could be a consequence of the methodological approach used in our work, because we estimated $\alpha$-diversity from raw data for each dataset, and not from published values. Our methodological choice was determined by the need to have standardized measures of $\beta$ diversity, which were not directly available from published values. Our sample size was sufficiently large to detect regional changes in species diversity but might not have provided enough power to detect changes in local species richness. The partitioning of multifactorial data (i.e., studies with more factors than warming alone) into independent subsets reduces the sample size within datasets, and heterogeneity is larger between smaller studies than larger studies (IntHout et al., 2015), which might have reduced our ability to detect changes in local species richness. Our approach, however, allowed us to analyse data consistently, producing comparable estimates of effect sizes, especially for $\beta$-diversity across studies.

Despite these differences between our results and those of Gruner et al. (2017), it is important to note that the effects of different components of global change on local species richness have been widely debated in recent years, with some proponents suggesting that, on average, species richness is not declining at local scales (e.g., Dornelas et al., 2014; Hillebrand et al., 2018; Vellend et al., 2017) and others suggesting that these claims might be based on poor or incomplete data and on the lack of well-defined temporal baselines for detecting changes in local species richness (e.g., Cardinale et al., 2018; Gonzalez et al., 2016). Recent syntheses have also shown that species richness does not decrease with warming (Antão et al., 2020; Suggitt et al., 2019; Yue et al., 2020). Observational studies have also demonstrated that climate has an important role in determining species richness at large scales, but cannot account for the variation in species richness at finer scales (Field et al., 2009). Our results support this notion that the lack of effect on average local species richness and the increase in spatial turnover of species composition seems to be a common consequence of numerous human-induced disturbances (Dornelas et al., 2014; Hillebrand et al., 2018), including climate warming (Dornelas et al., 2014; Hillebrand et al., 2010).

Our meta-analysis provides crucial information for understanding the consequences of climate change on meta-ecosystems, showing that spatial turnover becomes more common under warming scenarios. An understanding of changes in community composition across local communities as a consequence of warming is crucial to the choice of relevant spatial scales for conservation and the planning of protected areas (Bergamin et al., 2017; Legendre et al., 2005). An important practical aspect to consider for conservation is that changes in community composition (i.e., $\beta$-diversity) provide information more relevant for conservation than less informative measures, such as indices of species richness and community diversity, which cannot account for differences among ecological communities or functional and evolutionary differences among species (Hekkala \& Roberge, 2018; Hillebrand et al., 2018). This aspect also applies to shifts in species dominance within communities, which respond faster to anthropogenic pressures than $\alpha$-richness (Hillebrand et al., 2008, 2018), as we observed for ENS.Pie.

Contrary to our initial expectation that experimental warming would create higher levels of nestedness owing to a systematic loss of species at the local scale, our results support the notion that warming promotes turnover in species composition by selecting species with distinct sets of traits when compared with initial and/ or control communities. This can correspond to two phenomena. In 
closed systems, the expansion of the upper bound of the temperature range in warmed treatments imposes a selection effect that seems idiosyncratic at the replicate level. In other words, warming seems to facilitate the establishment of different thermal-tolerant species in different replicates. In open systems, a wider range of temperature conditions is available (i.e., both control and warmed replicates can be colonized by species from the "regional" pool). This allows species to inhabit different parts of the thermal gradient. Such differential species sorting across the extended temperature gradient can lead to larger $\beta$-diversity values. In agreement with our results, species turnover has been shown to be the dominant component of total $\beta$-diversity in most ecological systems, independent of taxonomic group or geographical region (Soininen et al., 2018). Under increasing temperatures, taxonomic and functional turnover seems also to be a recurrent pattern (Frainer et al., 2017; Hillebrand et al., 2010; Gibson-Reinemer et al., 2015), creating novel communities (Lurgi et al., 2012; Urban et al., 2012; Williams \& Jackson, 2007).

Numerous mechanisms, such as random reshuffling, species invasion and idiosyncratic rates of range shift, have been proposed as explanations for climate-driven spatial turnover (Gibson-Reinemer et al., 2015). However, an increase in species turnover suggests that experimental communities are undergoing a process of species sorting, whereby warming changes the amplitude of temperature niches of species within communities, with pre-adapted species replacing resident ones along the temperature gradient (Loeuille \& Leibold, 2008). Species sorting has been suggested as a major mechanism in experimental warming studies for a broad range of taxa, inducing shifts in the selection of traits across the gradient (Elmendorf et al., 2012; Frainer et al., 2017; Gibson-Reinemer et al., 2015). Higher spatial turnover and its consequent novel assemblages nevertheless impose an extra and crucial implication for climate scientists and policy-makers, because they suggest that ecological communities might not be able to track climate change by shifting their ranges, even though species can (Gibson-Reinemer et al., 2015).

\subsection{Explaining heterogeneous effects of warming on components of diversity}

Physiological responses to environmental temperature, such as thermal scaling of performance (i.e., changes in species growth, energy gain and activity patterns as a function of temperature) can determine the result of competitive interactions among species (Buckley \& Roughgarden, 2006; Finstad et al., 2011). Thermal scaling might ultimately cause competitive exclusion owing to niche retractions (Finstad et al., 2011). Competitive displacement is also an important mechanism changing community composition and turnover, which act in consonance with environmental filtering (Leibold \& Chase, 2017). Besides changes in community composition itself, warming also has an effect on community structure, by altering competitive dominance and, consequently, species abundance (Harte \& Shaw, 1995; Hillebrand et al., 2018), which might also explain the decreases in ENS.Pie we have observed in our results. As we mentioned before, warming seems to promote species sorting, selecting species with new sets of traits and adaptations, which might be suboptimal at control temperatures. This new set of traits might lead to competitive advantages and boost the dominance of new species (Dangles et al., 2008; Kosten et al., 2012).

Patch openness had no significant effect on any component of diversity. Although rescue from deleterious disturbance, such as warming, depends on the potential for species to disperse and recolonize previously occupied patches, the relationship between dispersal and species diversity is complex, spatially contingent (Cadotte, 2006) and strongly dependent on other biotic and abiotic factors (Shanafelt et al., 2018). The relationship between dispersal and species diversity can display a unimodal curve, with diversity being maximized at intermediate levels of dispersal, and not at higher dispersal levels (Cadotte, 2006; Shanafelt et al., 2018). Consequently, open systems with higher rates of immigration do not necessarily retain more diversity than closed systems, and system openness might even have negative effects on local species richness in warmed systems (Gruner et al., 2017). We used patch openness as a proxy for habitat isolation, which, together with habitat fragmentation, has been considered historically as one of the main threats to biodiversity (Haddad et al., 2015; Quinn \& Harrison, 1988). However, it has recently been pointed out that fragmentation alone might not be as deleterious as previously thought (Fahrig, 2017, 2018; but see Fletcher et al., 2018), and habitat configuration might be more important than fragmentation per se (Årevall et al., 2018). This calls attention to the necessity of evaluating other habitat-related issues in warming experiments, such as habitat availability and configuration, in addition to the inherent ability of species to disperse.

Average $I^{2}$ values suggest that most of the variability across studies is attributable to heterogeneity rather than chance alone, especially for results from $\alpha$-diversity analyses, which were more heterogeneous than those for $\beta$-diversity. Heterogeneity in the effects of warming on diversity depends on the experimental system for different components of inventory diversity (both $\alpha$ - and $\gamma$-diversity). It has been shown that experimental marine systems tend to have higher average losses of species at the local level compared with terrestrial and freshwater systems (Gruner et al., 2017), which differs from our results, in which marine and terrestrial systems tended to gain more species than freshwater systems. However, time series from non-experimental marine communities show that species richness tends to increase with warming (Antão et al., 2020).

Contrary to our initial expectation, longer studies with higher $\Delta T$ did not have larger losses of species nor more nested communities as a consequence of sequential loss of diversity, despite evidence that both components of $\beta$-diversity change monotonically over time (Angeler, 2013). Our results for the effects of study length on local species richness and ENS.Pie are in agreement with the meta-analysis of Gruner et al. (2017), who also reported that study duration had no effect on $\alpha$-diversity. Despite the relative importance of study duration for $\gamma$-diversity, our results for $\alpha$ - and $\beta$-diversity reinforce the notion that temperature change can be the main driver of changes in species composition, creating rapid 
changes and novel assembled communities across the warming gradient (Gibson-Reinemer et al., 2015), regardless of the duration of exposure.

\section{3 | Conclusions and way forward}

Despite decades of research on the effects of warming on species diversity, only recently have we started to have robust syntheses of its effects in experimental meta-ecosystems (e.g., Gruner et al., 2017; Marino et al., 2018). However, most of the information available has been focused on local communities, with warming effects at the regional scale commonly being neglected. Despite the acknowledged limitations of our meta-analysis and the inherent difficulties in translating lessons learned from experimental to real meta-ecosystems, our results support the need for a refocusing of the agenda on the consequences of global change for biodiversity. The focus should shift from effects on local richness only to the full understanding of the effects on biodiversity at the regional scale. This poses important challenges for both experimental and observational designs. Although warming experiments have become more complex in recent years, with an ever-increasing number of factors considered, we still lack appropriate protocols to detect changes in communities across spatial scales and across a large number of taxa and ecosystem types. Although our results showed that patch isolation per se might not be as deleterious as it is generally assumed, an improvement in our understanding of the interaction between environmental perturbations, such as warming and fragmentation, is crucial to predict the future of our ecosystems in an increasingly modified world.

\section{ACKNOWLEDGMENTS}

We thank all researchers who provided data and/or replied to our questionnaires. This project was supported by the the Combined Effects of Climatic Warming and Habitat Fragmentation on Biodiversity, Community Dynamics and Ecosystem Functioning (FRAGCLIM) Consolidator Grant (number 726176) to J.M.M. from the European Research Council under the European Union's Horizon 2020 Research and Innovation Program. V.A.G.B., N.G. and J.M.M. received support from the Towards an Unified Theory of Biological Interactions (TULIP) Laboratory of Excellence (ANR-10-LABX-41 and 394 ANR-11-IDEX-002-02), from a Region Midi-Pyrenees project (CNRS 121090). M.E., R.O. and J.P. were funded by the Spanish Government (grant CGL2016-79835-P) and the European Research Council Synergy (grant ERC-SyG-2013-610028 IMBALANCE-P). We thank the editors and reviewers for their valuable comments and suggestions.

\section{DATA AVAILABILITY STATEMENT}

No primary data were originated by our study. All data are thirdparty datasets and are available in the published literature and listed in the Supporting Information (Appendix S1, Data sources). R codes are available at GitHub (https://github.com/bastazini/-The-impac t-of-climate-warming-on-species-diversity-across-scales/blob/ main/README.md).

\section{ORCID}

Vinicius A. G. Bastazini (iD https://orcid.org/0000-0001-5270-0621 José M. Montoya iD https://orcid.org/0000-0002-6676-7592

\section{REFERENCES}

Angeler, D. G. (2013). Revealing a conservation challenge through partitioned long-term beta diversity: Increasing turnover and decreasing nestedness of boreal lake metacommunities. Diversity and Distributions, 19, 772-781. https://doi.org/10.1111/ddi.12029

Antão, L. H., Bates, A. E., Blowes, S. A., Waldock, C., Supp, S. R., Magurran, A. E., Dornelas, M., \& Schipper, A. M. (2020). Temperature-related biodiversity change across temperate marine and terrestrial systems. Nature Ecology \& Evolution, 4, 927-933. https://doi.org/10.1038/ s41559-020-1185-7

Araújo, M. B., \& Luoto, M. (2007). The importance of biotic interactions for modelling species distributions under climate change. Global Ecology and Biogeography, 16, 743-753. https://doi. org/10.1111/j.1466-8238.2007.00359.x

Årevall, J., Early, R., Estrada, A., Wennergren, U., \& Eklöf, A. C. (2018). Conditions for successful range shifts under climate change: The role of species dispersal and landscape configuration. Diversity and Distributions, 24, 1598-1611. https://doi.org/10.1111/ddi.12793

Baselga, A. (2010). Partitioning the turnover and nestedness components of beta diversity. Global Ecology and Biogeography, 19, 134-143. https://doi.org/10.1111/j.1466-8238.2009.00490.x

Baselga, A. (2013). Multiple site dissimilarity quantifies compositional heterogeneity among several sites, while average pairwise dissimilarity may be misleading. Ecography, 36, 124-128. https://doi. org/10.1111/j.1600-0587.2012.00124.x

Baselga, A., Jiménez-Valverde, A., \& Niccolini, G. (2007). A multiple-site similarity measure independent of richness. Biology Letters, 3, 642645. https://doi.org/10.1098/rsbl.2007.0449

Bergamin, R. S., Bastazini, V. A. G., Vélez-Martin, E., Debastiani, V., Zanini, K. J., Loyola, R., \& Müller, S. C. (2017). Linking beta diversity patterns to protected areas: Lessons from the Brazilian Atlantic Rainforest. Biodiversity and Conservation, 26, 1557-1568. https://doi. org/10.1007/s10531-017-1315-y

Borenstein, M., Hedges, L. V., Higgins, J. P., \& Rothstein, H. R. (2009). Introduction to meta-analysis. John Wiley \& Sons.

Buckley, L. B., \& Roughgarden, J. (2006). Climate, competition, and the coexistence of island lizards. Functional Ecology, 20, 315-322. https:// doi.org/10.1111/j.1365-2435.2006.01095.x

Bulling, M. T., Hicks, N., Murray, L., Paterson, D. M., Raffaelli, D., White, P. C., \& Solan, M. (2010). Marine biodiversity-ecosystem functions under uncertain environmental futures. Philosophical Transactions of the Royal Society B: Biological Sciences, 365(1549), 2107-2116. https://doi.org/10.1098/rstb.2010.0022

Burnham, K. P., \& Anderson, D. R. (2002). Model selection and multimodel inference: A practical information-theoretic approach. Springer.

Cadotte, M. W. (2006). Dispersal and species diversity: A metaanalysis. The American Naturalist, 167, 913-924. https://doi. org/10.1086/504850

Cahill, A. E., Aiello-Lammens, M. E., Fisher-Reid, M. C., Hua, X., Karanewsky, C. J., Yeong Ryu, H., Sbeglia, G. C., Spagnolo, F., Waldron, J. B., Warsi, O., \& Wiens, J. J. (2013). How does climate change cause extinction? Proceedings of the Royal Society $B$ : Biological Sciences, 280(1750), 20121890. https://doi.org/10.1098/ rspb.2012.1890

Cardinale, B. J., Gonzalez, A., Allington, G. R., \& Loreau, M. (2018). Is local biodiversity declining or not? A summary of the debate over 
analysis of species richness time trends. Biological Conservation, 219, 175-183. https://doi.org/10.1016/j.biocon.2017.12.021

Chase, J. M., \& Knight, T. M. (2013). Scale-dependent effect sizes of ecological drivers on biodiversity: Why standardised sampling is not enough. Ecology Letters, 16, 17-26. https://doi.org/10.1111/ ele.12112

Chase, J. M., McGill, B. J., McGlinn, D. J., May, F., Blowes, S. A., Xiao, X., Knight, T. M., Purschke, O., \& Gotelli, N. J. (2018). Embracing scale-dependence to achieve a deeper understanding of biodiversity and its change across communities. Ecology Letters, 21, 1737-1751. https://doi.org/10.1111/ele.13151

Dangles, O., Carpio, C., Barragan, A. R., Zeddam, J. L., \& Silvain, J. F. (2008). Temperature as a key driver of ecological sorting among invasive pest species in the tropical Andes. Ecological Applications, 18 1795-1809. https://doi.org/10.1890/07-1638.1

Dornelas, M., Gotelli, N. J., McGill, B., Shimadzu, H., Moyes, F., Sievers, C., \& Magurran, A. E. (2014). Assemblage time series reveal biodiversity change but not systematic loss. Science, 344(6181), 296-299. https://doi.org/10.1126/science.1248484

Elmendorf, S. C., Henry, G. H. R., Hollister, R. D., Björk, R. G., Bjorkman, A. D., Callaghan, T. V., Collier, L. S., Cooper, E. J., Cornelissen, J. H. C., Day, T. A., Fosaa, A. M., Gould, W. A., Grétarsdóttir, J., Harte, J., Hermanutz, L., Hik, D. S., Hofgaard, A., Jarrad, F., Jónsdóttir, I. S., ... Wookey, P. A. (2012). Global assessment of experimental climate warming on tundra vegetation: Heterogeneity over space and time. Ecology Letters, 15, 164-175. https://doi. org/10.1111/j.1461-0248.2011.01716.x

Fahrig, L. (2017). Ecological responses to habitat fragmentation per se. Annual Review of Ecology, Evolution, and Systematics, 48, 1-23. https:// doi.org/10.1146/annurev-ecolsys-110316-022612

Fahrig, L. (2018). Forty years of bias in habitat fragmentation research. Chapter 5. In P. Kareiva, B. Silliman, \& M. Marvier (Eds), Effective conservation science: Data not dogma (pp. 32-38). Oxford University Press.

Field, R., Hawkins, B. A., Cornell, H. V., Currie, D. J., Diniz-Filho, J. A. F., Guégan, J.-F., Kaufman, D. M., Kerr, J. T., Mittelbach, G. G., Oberdorff, T., O'Brien, E. M., \& Turner, J. R. G. (2009). Spatial species-richness gradients across scales: A meta-analysis. Journal of Biogeography, 36, 132-147. https://doi.org/10.1111/j.1365-2699.2008.01963.x

Finstad, A. G., Forseth, T., Jonsson, B., Bellier, E., Hesthagen, T., Jensen, A. J., Hessen, D. O., \& Foldvik, A. (2011). Competitive exclusion along climate gradients: Energy efficiency influences the distribution of two salmonid fishes. Global Change Biology, 17, 1703-1711. https:// doi.org/10.1111/j.1365-2486.2010.02335.x

Fletcher, R. J. Jr., Didham, R. K., Banks-Leite, C., Barlow, J., Ewers, R. M., Rosindell, J., Holt, R. D., Gonzalez, A., Pardini, R., Damschen, E. I., \& Melo, F. P. (2018). Is habitat fragmentation good for biodiversity? Biological Conservation, 226, 9-15.

Frainer, A., Primicerio, R., Kortsch, S., Aune, M., Dolgov, A. V., Fossheim, M., \& Aschan, M. M. (2017). Climate-driven changes in functional biogeography of Arctic marine fish communities. Proceedings of the National Academy of Sciences USA, 114, 12202-12207. https://doi. org/10.1073/pnas.1706080114

Gibson-Reinemer, D. K., Sheldon, K. S., \& Rahel, F. J. (2015). Climate change creates rapid species turnover in montane communities. Ecology and Evolution, 5, 2340-2347. https://doi.org/10.1002/ ece3.1518

Gonzalez, A., Cardinale, B. J., Allington, G. R. H., Byrnes, J., Endsley, K. A., Brown, D. G., Hooper, D. U., Isbell, F., O'Connor, M. I., \& Loreau, M. (2016). Estimating local biodiversity change: A critique of papers claiming no net loss of local diversity. Ecology, 97, 1949-1960. https:// doi.org/10.1890/15-1759.1

Gruner, D. S., Bracken, M. E. S., Berger, S. A., Eriksson, B. K., Gamfeldt L., Matthiessen, B., Moorthi, S., Sommer, U., \& Hillebrand, H. (2017). Effects of experimental warming on biodiversity depend on ecosystem type and local species composition. Oikos, 126, 8-17. https://doi.org/10.1111/oik.03688

Haddad, N. M., Brudvig, L. A., Clobert, J., Davies, K. F., Gonzalez, A., Holt, R. D., Lovejoy, T. E., Sexton, J. O., Austin, M. P., Collins, C. D., Cook, W. M., Damschen, E. I., Ewers, R. M., Foster, B. L., Jenkins, C. N., King, A. J., Laurance, W. F., Levey, D. J., Margules, C. R., ... Townshend, J. R. (2015). Habitat fragmentation and its lasting impact on Earth's ecosystems. Science Advances, 1, e1500052. https://doi.org/10.1126/ sciadv.1500052

Harte, J., \& Shaw, R. (1995). Shifting dominance within a montane vegetation community: Results of a climate-warming experiment. Science, 267(5199), 876-880. https://doi.org/10.1126/science.267.5199.876

Hekkala, A. M., \& Roberge, J. M. (2018). The use of response measures in meta-analyses of land-use impacts on ecological communities: A review and the way forward. Biodiversity and Conservation, 27, 29893005. https://doi.org/10.1007/s10531-018-1583-1

Higgins, J. P., Thompson, S. G., Deeks, J. J., \& Altman, D. G. (2003). Measuring inconsistency in meta-analyses. BMJ, 327(7414), 557560. https://doi.org/10.1136/bmj.327.7414.557

Hillebrand, H., Bennett, D. M., \& Cadotte, M. W. (2008). Consequences of dominance: A review of evenness effects on local and regional ecosystem processes. Ecology, 89, 1510-1520. https://doi. org/10.1890/07-1053.1

Hillebrand, H., Blasius, B., Borer, E. T., Chase, J. M., Downing, J. A., Eriksson, B. K., Filstrup, C. T., Harpole, W. S., Hodapp, D., Larsen, S., Lewandowska, A. M., Seabloom, E. W., Van de Waal, D. B., \& Ryabov, A. B. (2018). Biodiversity change is uncoupled from species richness trends: Consequences for conservation and monitoring. Journal of Applied Ecology, 55, 169-184. https://doi. org/10.1111/1365-2664.12959

Hillebrand, H., Soininen, J., \& Snoeijs, P. (2010). Warming leads to higher species turnover in a coastal ecosystem. Global Change Biology, 16 , 1181-1193. https://doi.org/10.1111/j.1365-2486.2009.02045.x

IntHout, J., loannidis, J. P. A., Borm, G. F., \& Goeman, J. J. (2015). Small studies are more heterogeneous than large ones: A meta-metaanalysis. Journal of Clinical Epidemiology, 68, 860-869. https://doi. org/10.1016/j.jclinepi.2015.03.017

Kosten, S., Huszar, V. L. M., Bécares, E., Costa, L. S., Donk, E., Hansson, L.-A., Jeppesen, E., Kruk, C., Lacerot, G., Mazzeo, N., Meester, L., Moss, B., Lürling, M., Nõges, T., Romo, S., \& Scheffer, M. (2012). Warmer climates boost cyanobacterial dominance in shallow lakes. Global Change Biology, 18, 118-126. https://doi. org/10.1111/j.1365-2486.2011.02488.x

Lee, C., Schlemme, C., Murray, J., \& Unsworth, R. (2015). The cost of climate change: Ecosystem services and wildland fires. Ecological Economics, 116, 261-269. https://doi.org/10.1016/j.ecole con.2015.04.020

Legendre, P., Borcard, D., \& Peres-Neto, P. R. (2005). Analyzing beta diversity: Partitioning the spatial variation of community composition data. Ecological Monographs, 75, 435-450. https://doi. org/10.1890/05-0549

Leibold, M. A., \& Chase, J. M. (2017). Metacommunity ecology. Princeton University Press.

Loeuille, N., \& Leibold, M. A. (2008). Evolution in metacommunities: On the relative importance of species sorting and monopolization in structuring communities. The American Naturalist, 171, 788-799. https://doi.org/10.1086/587745

Lurgi, M., López, B. C., \& Montoya, J. M. (2012). Novel communities from climate change. Philosophical Transactions of the Royal Society B: Biological Sciences, 367(1605), 2913-2922. https://doi.org/10.1098/ rstb. 2012.0238

Marino, N. D. A. C., Romero, G. Q., \& Farjalla, V. F. (2018). Geographical and experimental contexts modulate the effect of warming on topdown control: A meta-analysis. Ecology Letters, 21, 455-466. https:// doi.org/10.1111/ele.12913 
McGlinn, D. J., Xiao, X., May, F., Gotelli, N. J., Engel, T., Blowes, S. A., Knight, T. M., Purschke, O., Chase, J. M., \& McGill, B. J. (2019). Measurement of Biodiversity (MoB): A method to separate the scaledependent effects of species abundance distribution, density, and aggregation on diversity change. Methods in Ecology and Evolution, 10, 258-269. https://doi.org/10.1111/2041-210X.13102

Oliver, T. H., Marshall, H. H., Morecroft, M. D., Brereton, T., Prudhomme, C., \& Huntingford, C. (2015). Interacting effects of climate change and habitat fragmentation on drought-sensitive butterflies. Nature Climate Change, 5, 941-945. https://doi. org/10.1038/nclimate2746

Opdam, P., \& Wascher, D. (2004). Climate change meets habitat fragmentation: Linking landscape and biogeographical scale levels in research and conservation. Biological Conservation, 117, 285-297. https://doi. org/10.1016/j.biocon.2003.12.008

Pecl, G. T., Araújo, M. B., Bell, J. D., Blanchard, J., Bonebrake, T. C., Chen, I.-C., Clark, T. D., Colwell, R. K., Danielsen, F., Evengård, B., Falconi, L., Ferrier, S., Frusher, S., Garcia, R. A., Griffis, R. B., Hobday, A. J., Janion-Scheepers, C., Jarzyna, M. A., Jennings, S., ... Williams, S. E. (2017). Biodiversity redistribution under climate change: Impacts on ecosystems and human well-being. Science, 355(6332), eaai9214. https://doi.org/10.1126/science.aai9214.

Peñuelas, J., Sardans, J., Estiarte, M., Ogaya, R., Carnicer, J., Coll, M., Barbeta, A., Rivas-Ubach, A., Llusià, J., Garbulsky, M., Filella, I., \& Jump, A. S. (2013). Evidence of current impact of climate change on life: A walk from genes to the biosphere. Global Change Biology, 19, 2303-2338. https://doi.org/10.1111/gcb.12143

Peñuelas, J., Sardans, J., Filella, I., Estiarte, M., Llusià, J., Ogaya, R., Carnicer, J., Bartrons, M., Rivas-Ubach, A., Grau, O., Peguero, G., Margalef, O., Pla-Rabés, S., Stefanescu, C., Asensio, D., Preece, C., Liu, L., Verger, A., Barbeta, A., ... Terradas, J. (2017). Impacts of global change on Mediterranean forests and their services. Forests, 8, 463. https://doi.org/10.3390/f8120463

Quinn, J. F., \& Harrison, S. P. (1988). Effects of habitat fragmentation and isolation on species richness: Evidence from biogeographic patterns. Oecologia, 75, 132-140. https://doi.org/10.1007/BF00378826

R Core Team (2012). R: A language and environment for statistical computing. R Foundation for Statistical Computing.

Scheffers, B. R., De Meester, L., Bridge, T. C. L., Hoffmann, A. A., Pandolfi, J. M., Corlett, R. T., Butchart, S. H. M., Pearce-Kelly, P., Kovacs, K. M., Dudgeon, D., Pacifici, M., Rondinini, C., Foden, W. B., Martin, T. G., Mora, C., Bickford, D., \& Watson, J. E. M. (2016). The broad footprint of climate change from genes to biomes to people. Science, 354(6313), aaf7671. https://doi.org/10.1126/ science.aaf7671.

Schuler, M. S., Chase, J. M., \& Knight, T. M. (2017). Habitat patch size alters the importance of dispersal for species diversity in an experimental freshwater community. Ecology and Evolution, 7, 5774-5783. https://doi.org/10.1002/ece3.2858

Shanafelt, D. W., Clobert, J., Fenichel, E. P., Hochberg, M. E., Kinzig, A., Loreau, M., Marquet, P. A., \& Perrings, C. (2018). Species dispersal and biodiversity in human-dominated metacommunities. Journal of Theoretical Biology, 457, 199-210. https://doi.org/10.1016/j. jtbi.2018.08.041

Soininen, J., Heino, J., \& Wang, J. (2018). A meta-analysis of nestedness and turnover components of beta diversity across organisms and ecosystems. Global Ecology and Biogeography, 27, 96-109. https://doi. org/10.1111/geb.12660

Stern, N. (2015). Why are we waiting?: The logic, urgency, and promise of tackling climate change. MIT Press.
Stewart, R. I., Dossena, M., Bohan, D. A., Jeppesen, E., Kordas, R. L., Ledger, M. E., ... Suttle, B. (2013). Mesocosm experiments as a tool for ecological climate-change research. In G. Woodward \& E. J. O'Gorman (Eds), Advances in ecological research (Vol. 48, pp. 71-181). Academic Press.

Stocker, T. F., Qin, D., Plattner, G.-K., Tignor, M. M. B., Allen, S. K., Boschung, J., Nauels, A., Xia, Y., Bex, V., Midgley, P. M., Alexander, L. V., Allen, S. K., Bindoff, N. L., Breon, F.-M., Church, J. A., Cubasch, U., Emori, S., Forster, P., Friedlingstein, P., ... Wuebbles, D. (2013). Climate change 2013. The physical science basis. Working group I contribution to the fifth assessment report of the intergovernmental panel on climate change - Abstract for decision-makers.

Suggitt, A. J., Lister, D. G., \& Thomas, C. D. (2019). Widespread effects of climate change on local plant diversity. Current Biology, 29, 29052911. https://doi.org/10.1016/j.cub.2019.06.079

Urban, M. C. (2015). Accelerating extinction risk from climate change. Science, 348(6234), 571-573. https://doi.org/10.1126/science.aaa4984

Urban, M. C., Tewksbury, J. J., \& Sheldon, K. S. (2012). On a collision course: Competition and dispersal differences create no-analogue communities and cause extinctions during climate change. Proceedings of the Royal Society B: Biological Sciences, 279(1735), 2072-2080.

Vellend, M., Dornelas, M., Baeten, L., Beauséjour, R., Brown, C. D., De Frenne, P., Elmendorf, S. C., Gotelli, N. J., Moyes, F., Myers-Smith, I. H., Magurran, A. E., McGill, B. J., Shimadzu, H., \& Sievers, C. (2017). Estimates of local biodiversity change over time stand up to scrutiny. Ecology, 98, 583-590. https://doi.org/10.1002/ecy.1660

Wiens, J. J. (2016). Climate-related local extinctions are already widespread among plant and animal species. PLoS Biology, 14, e2001104. https://doi.org/10.1371/journal.pbio.2001104

Williams, J. W., \& Jackson, S. T. (2007). Novel climates, no-analog communities, and ecological surprises. Frontiers in Ecology and the Environment, 5, 475-482. https://doi.org/10.1890/070037

Yue, K., Jarvie, S., Senior, A. M., Van Meerbeek, K., Peng, Y., Ni, X., Wu, F., \& Svenning, J.-C. (2020). Changes in plant diversity and its relationship with productivity in response to nitrogen addition, warming and increased rainfall. Oikos, 129, 939-952. https://doi.org/10.1111/ oik.07006

Yvon-Durocher, G., Allen, A. P., Cellamare, M., Dossena, M., Gaston, K. J., Leitao, M., Montoya, J. M., Reuman, D. C., Woodward, G., \& Trimmer, M. (2015). Five years of experimental warming increases the biodiversity and productivity of phytoplankton. PLoS Biology, 13 e1002324. https://doi.org/10.1371/journal.pbio.1002324

Zarnetske, P. L., Skelly, D. K., \& Urban, M. C. (2012). Biotic multipliers of climate change. Science, 336(6088), 1516-1518. https://doi. org/10.1126/science.1222732

\section{SUPPORTING INFORMATION}

Additional Supporting Information may be found online in the Supporting Information section.

How to cite this article: Bastazini VAG, Galiana N, Hillebrand $\mathrm{H}$, et al. The impact of climate warming on species diversity across scales: Lessons from experimental meta-ecosystems. Global Ecol Biogeogr. 2021;30:1545-1554. https://doi. org/10.1111/geb.13308 